\title{
Ozone Therapy as treatment for severe cases without good evolution in ophthalmology [abstract]
}

\author{
Karla Tratsk
}

Brazil

\section{ABSTRACT}

\section{OPEN ACCESS}

\section{Citation}

Tratsk K. Ozone Therapy as treatment for severe cases without good evolution in ophthalmology [abstract].

Proceedings of The World Conference on Ozone Therapy in Medicine,

Dentistry and Veterinary. Ancona (Italy). September 22nd - 23rd - 24th , 2017. J Ozone Ther. 2019;3(4):30. doi: 10.7203/ jo3t.3.4.2019.15513

\section{Academic Editor \\ Jose Baeza-Noci, \\ School of Medicine, Valencia University, SPAIN}

\section{Editor}

World Federation of Ozone Therapy, Bolgna, ITALY

\section{Received}

June 17, 2019

\section{Accepted}

December 08, 2019

\section{Published}

December 30, 2019

\section{Intellectual Property}

Karla Tratsk.

This is an open access article distributed under the terms of the Creative Commons Attribution License (CC BY 4.0), which permits unrestricted use, distribution, and reproduction in any medium, provided the original author and source are credited.

\section{Author Information}

dra.karla@tratsk-nitz.com
Purpose. In ophthalmology many diseases lead to irreversible blindness, something that implies millions of dollars in care because people with these difficulties loose their autonomy, becoming dependent in all their everyday activities.

This presentation will focus on clinical cases of the following pathologies treated with Ozone Therapy because all these were already being treated in a conventional way without signs of improvement. They are primary openangle glaucoma, age-related macular degeneration, diabetic retinopathy, occlusion of the central retinal artery, facial paralysis and herpetic polyneuropathy associated with orbital apex syndrome.

Case Presentation. As an example, a patient, 73 , female, insulindependent diabetes for 10 years, with primary open angle glaucoma, diabetic retinopathy with various laser photocoagulations, vitrectomies and intravitreal injections in both eyes (BE). Visual acuity (VA) of 20/200 in right eye (RE) and 20/100 in left eye (LE).

Subjected to the facectomy in RE and with cataract in LE. The fundoscopy was stable in BE. The VA went to $20 / 200$ on 1 st day of postoperative period and remained stable until 21st day. After integrative treatment with Ozone Therapy the patient got a VA of 20/60-2 in RE and 20/40-2 in LE, restoring vision and improving her quality of life.

Furthermore, she stopped to be insulin dependent, only having to take oral medication.

Conclusions. The result shows that Ozone therapy should be a therapeutic tool to be associated with Ophthalmology because in many cases, including difficult treatment and evolution, it recovers visual acuity and re-establishes ocular physiology, promoting the maintenance of eye health and vision, contributing to the preservation of autonomy in the lives of patients.

\section{References:}

1. Bocci V. Ozone. A new medical drug. Netherlands: Springer, 2005

2. Viebahn-Hänsler R, Ozon-Sauerstoff-Therapie, ein praktisches Handbuch. $2^{\mathrm{a} e d}$. Stuttgart: Karl F. Haug Verlag, 20092007;6(4):279-294. 